\title{
IN SITU ESWL AND ESWL AFTER PUSH BACK FOR UPPER URETERIC CALCULI: A COMPARATIVE STUDY
}

\author{
S ISLAM ${ }^{1}$, SM KHAN ${ }^{2}$, S REGMI ${ }^{3}$, IA SHAMEEM ${ }^{4}$, GM CHOWDHURY $^{5}$, AKMK ALAM $^{6}$
}

\section{Abstract}

This prospective study has been done to compare the results of treatment of uncomplicated upper ureteral calculi by in situ ESWL and ESWL after push back. Ninety consecutive patients with single upper- ureteric stones of $<1 \mathrm{~cm}$ in size with no distal obstruction were selected and divided into two groups. Fifty patients in group 1 were treated by in situ ESWL while 40 patients in group 2 were treated by push back followed by ESWL. In the in situ ESWL group, $56 \%$ cases were cleared of stone otter I week of first session, $24 \%$ cases required second and $10 \%$ cases required third sessions for complete clearance of stone. Overall $90 \%$ clearance was achieved after 90 days in this group. In the ESWL after push back group, $52.5 \%$ cases were cleared of stone after- 1 week of first session, $30 \%$ cases required second and $10 \%$ cases required third sessions for complete clearance of stone. Overall $92.5 \%$ clearance was achieved after 90 days in this group. Although more clearance rate was achieved in ESWL after push back, it was not statistically significant $(p>0.05)$. The number of average ESWL sessions required was 1.54 for stone $\mathrm{cm}$ and 1.77 /or stone of $\mathrm{I} \mathrm{crn}$ in the in situ ESWL group, where as it was 1.46 and 1.48 respectively for stones $1 \mathrm{~cm}$ and of $1 \mathrm{~cm}$ respectively in the ESWL after push back group, however this difference was not statistically significant. More shock wave and energy was needed in the in situ ESWL group than in ESWL after push back group. The mean shock wave was $1994+449$ for in situ ESWL group and $1757.5 \pm 255$ for $17 S 117$, after push back group, which was statistically very significant $(p<0.01)$. The mean energy used was $5.07 \mathrm{~L} 0.81$ in the in situ ESWL group and 4.6 0.48 in ESWL after push back group and this difference was also statistically significant $(p<0.01)$. Post procedure complications like loin pain, noninvasive nature of ESWL has a strong appeal to the patients and physicians, and has become the first line treatment option for proximal ureteral stones. Although some urologists claim a higher success rate of ESWL after push back procedure, the invasiveness of the additional ureteral manipulation must be considered ${ }^{6}$. On the other hand, in situ ESWL for uncomplicated upper ureteric calculi is appealing because it is noninvasive, requires no anesthesia, low morbidity, low cost and can be performed as an outpatient therapy and offers acceptable results. So, this study has been done to compare the results of treatment of uncomplicated upper ureteral calculi by in situ ESWL and ESWL after push back.

\section{Materials and Methods}

This prospective study was done in the Department of Urology. Bangabandhu Sheikh Mujib Medical University from Jan 2009 to Dec 2009 after getting approval from the institutional review board. Ninty patients with single upper ureteric stones of $<1 \mathrm{~cm}$ in size with no distal obstruction were selected and divided into two groups. Stones located $<2$ em lateral to the spine. size $>\mathrm{Icm}$ in size, pregnant women and patients with bleeding disorders were excluded from the study. After taking the informed consent, 50 patients of group I was treated by in situ ESWL while 40 patients of group 2 was treated by push back followed by ESWL. In all case, ESWL was done by Siemens Lithoskop (3rd generation) lithotriptor.

All patients were thoroughly examined and routine investigations done. IVU was done in all patients to see the condition of kidneys, grade of hydronephrosis, location and size of stone. All patients were advised to take mild laxative and ultracarbon in the night before ESWL. All patients were nothing per oral from morning on the day of procedure and were given intravenous fluid \& diclofenac suppository half hour prior to the procedure. Additional analgesia or sedation was given on demand basis. In patients of group 2, a pre-ESWL push back procedure was done under general anesthesia and fluoroscopic guidance. After dislodging the stone back into the kidney, a DJ stent was kept in situ and ESWL was done.

After ESWL, all patients were advised to follow up after 7 days with a plain X-ray of KUB region, and if necessary second \& third session of ESWL were given at one week interval. If the stone fails to clear after third session, the patient was observed for 90 days to see stone clearance. Refractory cases were referred for other modalities of treatment. The data were analyzed using SPSS version 12. Students $t$ test and chi square test were used and p-value of $<0.05$ was considered significant. 


\section{Results}

The demographic and baseline characteristics of the patients are shown in table I.

Table-I

Demographic \& baseline characteristics among the groups.

\begin{tabular}{lcc}
\hline Characteristics & $\begin{array}{c}\text { Group I } \\
(\mathrm{N}=50)\end{array}$ & $\begin{array}{c}\text { Group II } \\
(\mathrm{N}=40)\end{array}$ \\
\hline $\begin{array}{l}\text { Mean age t SD } \\
\text { Range (years) }\end{array}$ & $\begin{array}{c}34.86+11.74 \\
\text { Sex distribution }\end{array}$ & $\begin{array}{c}35.12+14.48 \\
16-62\end{array}$ \\
$\begin{array}{l}\text { Male } \\
\text { Female }\end{array}$ & $32(64 \%)$ & $30(75 \%)$ \\
Involved ureter & $18(36 \%)$ & $10(25 \%)$ \\
Left & $35(70 \%)$ & $30(75 \%)$ \\
Right & $15(30 \%)$ & $10(25 \%)$ \\
Size of stone & & \\
$<1 \mathrm{~cm}$ & $28(56 \%)$ & $15(37.5 \%)$ \\
$1 \mathrm{~cm}$ & $22(44 \%)$ & $25(62.5 \%)$ \\
\hline
\end{tabular}

The outcome variables were stone clearance rates (table 11), ESWL sessions required, shock wave \& energy required, post procedure complications and hospital stay (table-II).

Table-II

Stone clearance rates between the groups.

\begin{tabular}{llcl}
\hline Stone clearance rates & $\begin{array}{c}\text { Group I } \\
\text { (in situ) }\end{array}$ & $\begin{array}{c}\text { Group II } \\
\text { (push back) }\end{array}$ & p-value \\
\hline
\end{tabular}

Clearance after 1st session

\begin{tabular}{|c|c|c|}
\hline$<1 \mathrm{~cm}$ & $18(36 \%)$ & $8(20 \%)$ \\
\hline $1 \mathrm{~cm}$ & $10(20 \%)$ & $13(32.5 \%)$ \\
\hline
\end{tabular}

Clearance after $2 \mathrm{nd}$ session

$\begin{array}{llll}<1 \mathrm{~cm} & 5(10 \%) & 5(12.5 \%) & >0.05 " \\ 1 \mathrm{~cm} & 7(14 \%) & 7(17.5 \%) & \end{array}$

Clearance after $3^{\text {rd }}$ session

$\begin{array}{llll}<\mathrm{lcm}) & 3(6 \%) & 2(5 \%) & >0.05 " \\ 1 \mathrm{~cm} & 2(4 \%) & 2(5 \%) & \end{array}$

Overall clearance after 90 days

\begin{tabular}{llll}
$<1 \mathrm{~cm})$ & $26(92.86 \%)$ & $15(100 \%)$ & $>0.05^{\prime \prime}$ \\
$1 \mathrm{~cm}$ & $19(86.36 \%)$ & $22(88 \%)$ & \\
\hline
\end{tabular}

" $\chi^{2 '}$ test was not significant
Table-III

Number of ESWL sessions, shock wave \& energy required, complication \& hospital stay between the groups.

\begin{tabular}{lccc}
\hline Variables & $\begin{array}{c}\text { Groupl } \\
\text { (in situ) }\end{array}$ & $\begin{array}{c}\text { Group 2 } \\
\text { (push back) }\end{array}$ & p-value \\
\hline Avg. &
\end{tabular}

Avg. ESWL sessions required $(\mathrm{n})$

$\begin{array}{llll}<1 \mathrm{~cm} & 1.54 & 1.46 & >0.05 \mathrm{n} \\ 1 \mathrm{~cm} & 1.77 & 1.48 & \end{array}$

Shock waves required $(n)$

Mean \pm SD $\quad 1994 \pm 4491757 \pm 255<0.01$

Range $\quad 1500-5000 \quad 1000-2000$

Energy required (KV)

$\begin{array}{lccc}\text { Mean } \pm S D & 5.07 \pm 0.81 & 4.63 \pm 0.48 & <0.01^{*} \\ \text { Range } & 4-8 & 4-6 & \end{array}$

Complications ( $\mathrm{n}$ )

LOTS

Loin pain

$12(24 \%) \quad 28(70 \%) \quad<0.00 \mathrm{P}$ $20(40 \%) \quad 25(62.5 \%) \quad<0.0 \mathrm{~V}$

Fever

Hematuria $5(10 \%) \quad 12(30 \%) \quad<0.0 \mathrm{~V}$

Hospital stay (days)

Mean \pm SD

$1.06 \pm 0.24 \quad 2.4 \pm 0.74<0.001$

Range

$1-2 \quad 2-5$

" $x$ test was not significant; * $t$ test was significant, " $x$ test was significant

\section{Discussion}

In the in situ ESWL group, 28 (56\%) cases were cleared of stone after 1 week of first session, among which 18 $(36 \%)$ were $<1 \mathrm{~cm}$ in size and $10(20 \%)$ were I cm in size. However, the higher clearance rate of the smaller stones was not statistically significant. It was also observed that $12(24 \%)$ cases required second and 5 $(10 \%)$ cases required third sessions for complete clearance of stone. Overall clearance was achieved in $45(90 \%)$ cases after 90 days in this group. These findings are similar to those by El-Gammal et al. (1992) who reported $94.8 \%$ clearance rate for upper ureteric stones treated by EWSL in situ with $66.7 \%$ patient stone free after first session, $17.7 \%$ needed two sessions and $8.5 \%$ required three sessions'. Similarly, Shameen et al. (2001) also reported good results with $96.6 \%$ stone free rates in a study. on 118 patients of ureteral stones of mean $11.1 \mathrm{~mm}$ in size treated with in situ ESWL using Lithostar plus lithotriptor ${ }^{8}$. 
In the ESWL after push back group, 21 (52.5\%) cases were cleared of stone after 1 week of first session, among which $8(20 \%)$ were $<1 \mathrm{~cm}$ in size and $13(32.5 \%)$ were $\mathrm{I} \mathrm{cm}$ in size. However, the higher clearance rate of the larger stones was not statistically significant. It was also observed that $12(30 \%)$ cases required second and $4(10 \%)$ cases required third sessions for complete clearance of stone. Overall clearance was achieved in $37(92.5 \%)$ cases after 90 days in this group. Although more clearance rate was achieved in ESWL after push back, it was not statistically significant $(p>0.05)$. Danuser ct al. (1993) also reported $96 \%$ stone free rates at 3 months after ESWL_ in situ and $94 \%$ stone free rate at 3 months after push back followed by ESWL). Similarly, Kumar et al. (1994) in a similar comparative study showed $80 \%$ clearance rate in group 1 and $88.5 \%$ clearance in group 2 at 3 months. These results compare favorably with our study although making comparison between them is difficult since the criteria for disintegration and the type of lithotripter used varied.

The number of average ESWL sessions in our study was 1.54 for stone $<1 \mathrm{~cm}$ and 1.77 for stone of $\mathrm{I} \mathrm{cm}$ in the in situ ESWL group (group 1). where as it was 1.46 and 1.48 respectively for stones $<1 \mathrm{~cm}$ and of $\mathrm{I} \mathrm{cm}$ respectively in the push back followed by ESWL group (group 2). Although less number of ESWL sessions were required in push back group, it was not statistically significant. In a study by Kumar et al. (1994), the number of average sessions was $1.86 \quad 1.2$ and $2.03 \quad 1.2$ respectively for in situ ESWL \& ESWL after push back ${ }^{8}$.

In our study, more shock wave and energy was needed in the in situ ESWL, group than in ESWL after push back group. The mean shock wave was 1994449 for group 1 and 1757.5255 for group 2. The difference between the two groups was statistically very significant $(p<0.01)$. The mean energy used was 5.070 .81 in group 1 and 4.6 t 0.48 in group 2 and this difference was also statistically significant $(p<0.01)$. However, Danuser et al. (1993) found that more shock wave and energy was required for in situ ESWL rather than ESWL after push back.

Post procedure complications like loin pain, hematuria, lower urinary tract symptoms (LUTS) and fever were more common in group 2 than in group 1 in our study and the differences were statistically highly significant. All these complications were treated by conservative measures. Similarly, the mean hospital stay was $1.06+$ 0.24 days for group 1 while it was $2.4+0.74$ days for group 2 which is again highly significant $(p<0.001)$.
Hendrix et al. (1990) in a similar study reported an average hospital stay of 0.85 and 1.2 days for in situ ESWL and ESWL after push back groups respectively.

Although exact cost of the procedure could not be determined because the service charges among the patients were not homogenous due to the provision of free and paying beds. However, the cost of group 2 was higher due to the charges for the push back procedure in addition to the charges of ESWL. For ESWL and patients in group I, they have to pay only a one time charge of Taka 15000 irrespective of the number of sessions required. Moreover, the mean hospital stay in group 2 was longer with more working day loss for the patient. Thus, ESWL after push back was costlier than in situ ESWL.

\section{Conclusion}

Considering the findings of this study, it can be concluded that in situ ESWL is a better option than ESWL after push back for the management of upper ureteric stones in selected group of patients and thereby avoids a more invasive procedure. Besides, ESWL after push back may be reserved for the case that fails to clear the stones after in situ ESWL. A major limitation of this study was the non homogenous nature of study subjects, so further study with homogenous and large sample size is recommended to determine the optimum treatment option for upper ureteric stones more precisely.

\section{References}

1. Stoller, ML \& Bolton, DM 2000, 'Urinary stone disease', In Tanagho, EA \& McAninch. JW (eds), Smith's General Urology, $15 \mathrm{t}^{\mathrm{h}}$ ed, McGraw Hill, New York, pp.291-320.

2. James. E \& Lingerman, MD 1997, 'Extracorporeal shock wave lithotripsy: development, instrumentation and current status'. Urologic Clinics of North America, vol. 24, pp. 185.

3. Weinberg. JJ, Snyder, JA \& Smith, AD 1988, 'Mechanical extraction of stones with rigid ureteroscopes'. North American Journal of Clinical Urology, vol. 15, pp, 339.

4. Dretler, SP 1988, 'Management of ureteral calculi', AUA update series, vol. 7, pp, 42, 5. Liong, ML, Clayman, RV, Gittes, RF, Lingerman, JE, Huffman. JL \& Lyon, ES 1988- 'Treatment options for proximal ureteral urolithiasis: review and recommendations', The Journal of Urology, vol. 140, pp. 504-507, 
6. Danuser, H. Ackerman. DK, Marth, DC, Studer, UE \& Zingg. EJ 1993, 'Extracorporeal shock wave lithotripsy in situ or after push up for upper ureteric calculi', The Journal of Urology, vol. 150, pp. 824826,

7, El-Gammal. MY, Fouda, AA, Meshraf, AW, AbuEl-Magd, ANM, Farag, FA \& El-Katib, SE 1992, 'Management of ureteral stones by extracorporeal shoch wave lithotripsy using Lithostar lithotripter', The Journal of Urology, vol. 148, pp, 1086-1087.

8. Shameen, IA, Islam, K, Islam, AKMA, Salam, MA \& Wahab, MA 2001, 'Management of ureteral stones by in situ ESWL', Bangladesh Journal of Urology, vol. 4, pp, 14-15.

9. Kumar, A, Kumar, VR, Mishra, VK, Ahlawat, R, Kapoor, R \& Bhandari, M 1994, 'Should upper ureteric calculi be manipulated before extracorporeal shock wave lithotripsy? A prospective controlled trial', The Journal of Urology, vol. 152, pp. 320-323.

10. Hendrix, AJM, Bierkens, AF, Oosterhof, GON \& Debuyne, FMJ 1990, 'Treatment of proximal and mid-ureteral calculi: a randomized trial of in situ and push back extracorporeal lithotripsy', Journal of Endourology, vol. 4, pp, 353,

\section{Authors}

1. Assistant Professor of Urology, BSMMU.

2. Assistant Professor of Urology, CMC.

3. MS (Urology) Final part student, BSMMU.

4. Associate Professor of Pediatric Urology, BSMMU.

5. Associate Professor of Uro-oncology, BSMMU.

6. Associate Professor of Urology, BSMMU. 